\title{
Numerical Analysis of Fluid Flow in Aquaculture Systems
}

\author{
Mohammad Shallouf $^{1}$, Wael H. Ahmed ${ }^{1}$, Sherif Abdou ${ }^{2}$ \\ ${ }^{1}$ University of Guelph \\ 50 Stone Rd E, Guelph, Canada \\ mshallou@uoguelph.ca; ahmedw@uoguelph.ca \\ ${ }^{2}$ FloNergia Inc. \\ 994 Zelco Dr, Burlington, Canada \\ sherif.abdou@flonergia.com
}

\begin{abstract}
The aquaculture industry is currently experiencing a strong surge of interest due to its sustainable management and efficient land use. Unfortunately, the operating cost of such facilities has made it tougher to replace current conventional systems. There is a need to find better solutions to improve the operational efficiency of these systems to become more financially attractive. This work will present a numerical and experimental analysis of a dual injector airlift pump developed by Ahmed and Badr [1]. As well as a case study of an aquaculture raceway system with an integrated airlift pump system. Utilizing the Volume of Fluid (VOF) multi-phase model along with the K- $\varepsilon$ turbulence model, a numerical study using ANSYS Fluent 19.0 was performed for the two-phase flow of an aquaculture raceway system. The flow characteristics of the airlift pump injectors were studied under single phase flow conditions. These simulation results were used to scale an airlift pump to operate in a $3.5 \mathrm{~m}^{3}$ raceway system. The numerical results had an average RMS agreement of $\pm 15 \%$ with the experimental results. The present study was found to present a great tool for optimizing the airlift pump design, as well as modifying the design of future aquaculture systems or other two-phase flow applications.
\end{abstract}

Keywords: Airlift Pump, Aquaculture, Two-Phase Flow, CFD.

\section{Introduction}

Aquaculture is projected to be the primary source of seafood by 2030 as it meets many environmental, economic and social sustainability goals [2]. Unfortunately, aquaculture has neither received the concentrated research effort that has been applied to many agriculture fields, nor has it enjoyed the same widespread use in comparison to traditional fisheries [3]. This has cast a bad reputation on the aquaculture industry as inefficient and economically expensive to implement. There is a definite need for more investigations to improve the design and operational methods of aquaculture systems by utilizing engineering principles. Such investigations can lead to an increase in the sustainability and economy of these systems. The usage of airlift pumps in aquaculture systems has been recognized for its potential benefits since the seventies. Aquaculture facilities require the aeration of the water supply to increase oxygen levels in the system and the pumping of water to create an appropriate flow through the system. This has typically required two separate systems. Wheaton [3] recognized that airlift pumps can combine both functions into a single system that can aerate the water supply while simultaneously pumping it. This observation along with other benefits of the airlift pump such as low initial costs, lower maintenance, easy installation, portability, and freedom from clogging [4] shows a strong benefit in integrating airlift pump systems into the aquaculture industry. Parker and Suttle [5] were one of the earliest researcher groups to specifically design an airlift pump system for aquaculture. They conducted experiments on airlift pumps with diameters ranging from 3.75 to $30 \mathrm{~cm}$ while having the pump at 100\% submergence. Similarly, Wurts et al. [6] conducted experiments using airlift pumps made from PVC piping with diameters ranging from 7.6 to $15.2 \mathrm{~cm}$. These experiments found that the ability of the airlift pump to pump, aerate, and agitate solid particles to be very suitable for floating raceways, open cages and recirculating aquaculture systems. Improvements on the airlift pump injector design can further increase its efficiency and its pumping ability. A new airlift pump injector developed by Ahmed and Badr involves combining two different injection methods to improve its pumping and aeration performance [1].

Recirculating aquaculture systems (RAS) are one of the major aquaculture systems currently in use as they are perceived as the best solution to meet future fish demands in a sustainable matter. These systems operate based on the ability to reuse 
the water in the system by letting it undergo several filtration processes. This significantly reduces the amount of water needed to run the system, as only a small amount of water is added with each cycle to compensate for the water loss due to evaporation and imperfect filtration [7]. RAS can be built both indoors or outdoors and therefore offer the greatest degree of flexibility amongst the aquaculture systems. This has allowed these systems to spread for commercial, educational, research and even non-profit applications all over the world. The benefits of RAS include meeting various sustainability, economic and engineering goals set by many world organizations [8]. The biggest disadvantage currently facing RAS is the high capital and operational costs required. Finding a solution that will make these systems more economically attractive will increase their wide spread commercially. Integrating airlift pumps into the operation of recirculating aquaculture systems is a potential solution that could better improve the operational efficiency of these systems.

The objective of this work is to present the airlift pump injector and study its hydrodynamic characteristics under singlephase conditions. Understanding the operation of the injectors can then aid in finding the best method of integrating it into an aquaculture system. Thus, a study of the fluid flow of an aquaculture raceway with an integrated airlift pump system was performed. This will help in finding whether the airlift pump system is capable of achieving the operational conditions of such systems.

\section{Experimental Analysis}

Two sets of experimental work were performed in this study. The first was conducted in the mechanical lab at the University of Guelph and was used to measure the pressure drop across the airlift pump injectors. The second set consisted of field work to study the operation of a raceway system by measuring the velocity profiles across the raceway.

The laboratory set up used to study the airlift pump injectors utilized two identical digital air mass flow meters (OMEGA FMA-LP1600). The mass flow meters were used to simultaneously measure the air flow rate, temperature and pressure readings at each of the injectors. The air is supplied through a main airline provided from the labs pneumatic system, which then splits to accommodate the two flow meters. Figure 1 provides a simple schematic of the setup used. The mass flow meter had a $\pm 8 \%$ uncertainty associated to its pressure measurement.

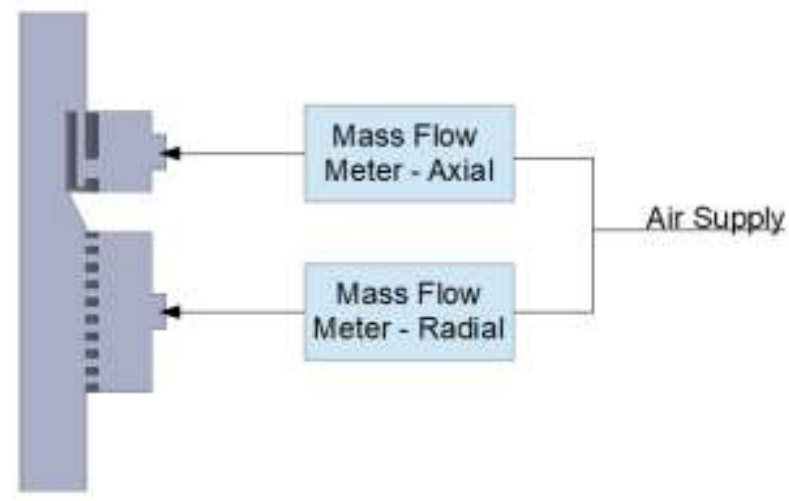

Fig. 1: Experimental Schematic.

The field trials occurred at an aquaculture facility in McMillian Pitts, Ontario, Canada where an airlift pump system was installed to study its effects on the operation of the raceway. The raceway system was built on a floating dock in a closed lake creating a recirculating system. A frame was built to fit the raceway and an airlift pump system was attached to it. This supplied the raceway with the needed operational flow rate. The airlift pump system was built out of PVC and consisted of four airlift pumps, each having a $1.016 \times 10^{-1} \mathrm{~m}$ inner diameter. The purpose of the field work was to study the velocity profiles across and along the raceway, as well at various depths. The velocity profiles provided baseline measurements which were then compared to the simulated results. These velocities were also important to the operation of the raceway, as a certain velocity was needed to aid in fish growth. Figure 2 demonstrates the field setup as well as the location layout of the velocity measurements recorded. 
The measurement instrumentation used was an acoustic Doppler velocimeter (ADV). An ADV is a device that measures the velocity of fluids by measuring the Doppler shift experienced by ultrasound radiation. A FlowTracker Handheld ADV was used in a $2 \mathrm{D}$ measurement configuration to measure the normal and tangent velocity components of the flow.

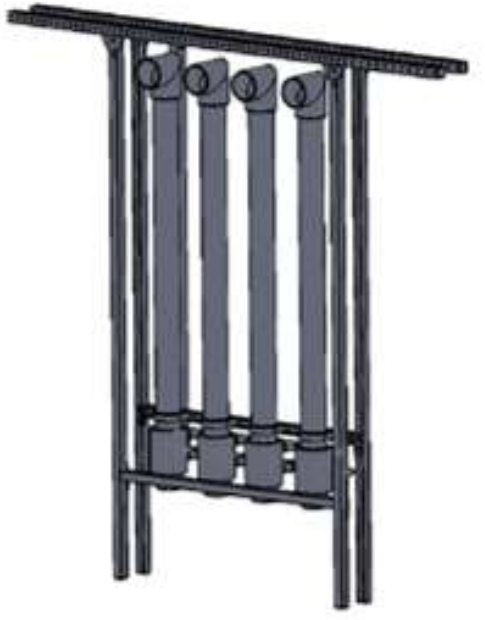

(a) Airlift Pump System

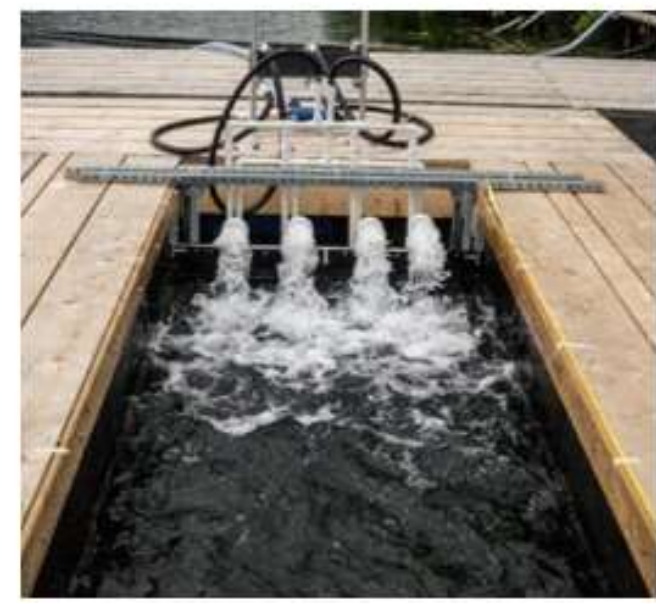

(b) Airlift Pump System in the Field

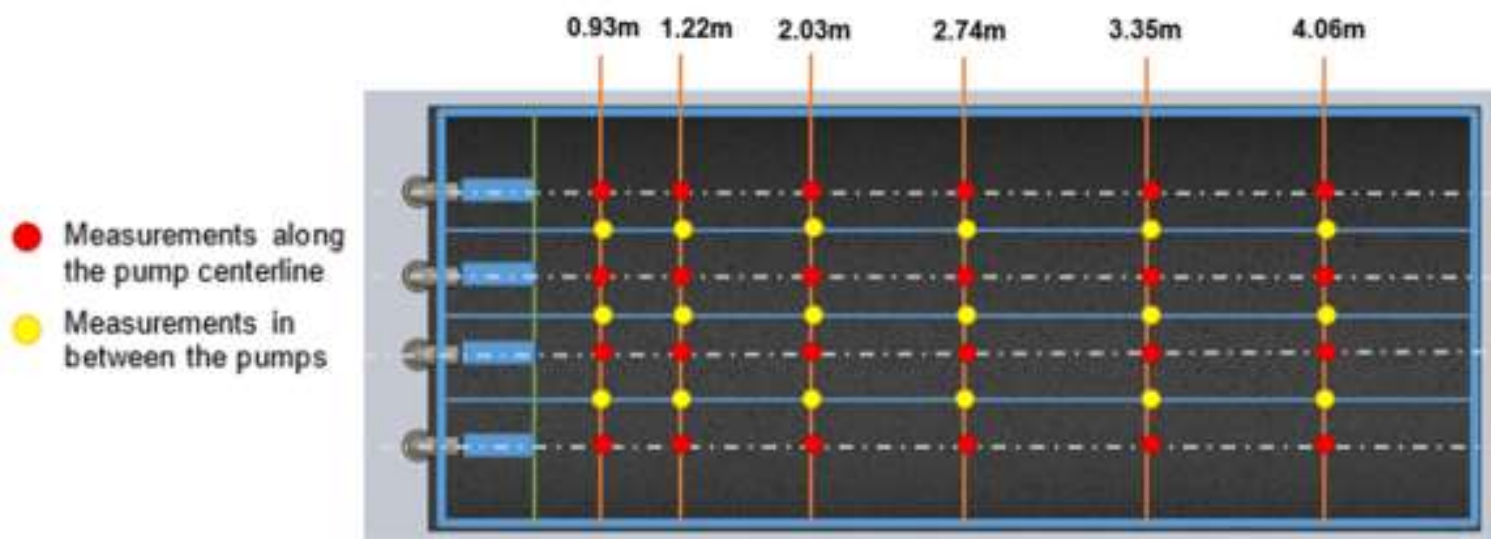

(c) Velocity Measurement Schematic

Fig. 2: Field Testing Setup and Measurement Schematic.

The device consisted of a single acoustic transmitter and two receivers. The transmitter generates a short pulse of sound at a known frequency, which reflects in all directions by the particulate matter in the water. The receivers are then able to pick up the reflected noise [9]. The velocimeter then measures the change in frequency at each receiver and used the Doppler shift principle to find the equivalent velocity.

The ADV was calibrated by placing the probe in stagnant water and ensuring that the output velocity was zero. The ADV reading uncertainty is typically $\pm 0.01 \mathrm{~m} / \mathrm{s}$, which, based on the magnitude of the velocities experienced, is nearly $15 \%$, and it is expected to increase in more turbulent flow regions. The ADV also has a $\pm 1 \%$ uncertainty in the speed of sound signal, which results in an additional $\pm 2 \%$ additional uncertainty in the velocity measurement. The velocimeter in the field was subjected to both turbulent and highly recirculating flows at the points closest to the airlift pump system, and so the uncertainty range was expected to be higher. 


\section{Numerical Analysis}

The Reynolds-averaged Navier-Stokes equations were used to model the fluid flow in the domain. The two-phase flow numerical model used was the Volume of Fluid (VOF) model as well as the K- $\varepsilon$ model for turbulence closure. The continuity and momentum equations for the VOF model are presented as [10]:

$$
\begin{gathered}
\frac{\partial}{\partial t}\left(\alpha_{p} \rho_{p}\right)+\nabla \cdot\left(\alpha_{p} \rho_{p} \vec{v}_{p}\right)=S_{\alpha_{p}}+\sum_{p=1}^{n}\left(\dot{m}_{q p}-\dot{m}_{p q}\right) \\
\frac{\partial}{\partial t}(\rho \vec{v})+\nabla \cdot(\rho \vec{v} \vec{v})=-\nabla p+\nabla \cdot\left[\mu\left(\nabla \vec{v}+\nabla \vec{v}^{T}\right)\right]+\rho \vec{g}+\vec{F}
\end{gathered}
$$

Whereas the void fraction tracking equation formulated by the VOF model is presented as:

$$
\begin{gathered}
\frac{1}{\rho_{q}}\left[\frac{\partial}{\partial t}\left(\alpha_{q} \rho_{q}\right)+\nabla \cdot\left(\alpha_{q} \rho_{q} \vec{v}_{q}\right)=S_{\alpha_{q}}+\sum_{p=1}^{n}\left(\dot{m}_{p q}-\dot{m}_{q p}\right)\right] \\
\sum_{p=1}^{n} \alpha_{p}=1
\end{gathered}
$$

Where the density and viscosity are presented based on the void fraction value found at each computational cell:

$$
\begin{gathered}
\rho=\alpha_{q} \rho_{q}+\left(1-\alpha_{q}\right) \\
\mu=\alpha_{q} \mu_{q}+\left(1-\alpha_{q}\right) \mu_{p}
\end{gathered}
$$

Where $\alpha$ is the void fraction, $\rho$ is the density, $v$ is velocity, $\mu$ is dynamic viscosity, $\dot{m}$ is mass transfer between the two phases ( $p$ and $q$ ), and $S$ is any source variable which in this study was zero. The discretised version of equations is applied to the meshed fluid domain along with the appropriate boundary conditions. A three-dimensional model was created for the dual injection airlift pump as well as the aquaculture raceway. For the airlift pump, the axial injector pushes air through an inner annulus to redirect its movement into the axial direction, while the radial injector consists of a perforated tube that provides air in the radial direction. The domain represents a quarter section of the airlift pump with a symmetry boundary condition set on each of the axial planes. The axial and radial injectors boundary conditions were specified as volumetric flow inlets with fluid rates ranging from $6-60 \mathrm{~m}^{3} / \mathrm{h}$. While the pressure inlet and outlet were specified at $0 \mathrm{~Pa}$ static pressure to represent them being open to the atmosphere.

For the numerical modelling of the aquaculture raceway, only one section was considered for the simulation. A square flow inlet boundary (pump outlet) was used in the model which has the same hydraulic dimeter of the actual circular pipe of airlift pump system. The boundary conditions applied to the mass flow inlet represent the maximum water and air flow generated from the airlift pump. This condition has a water mass flow rate of $27,000 \mathrm{~kg} / \mathrm{h}$ and $22.68 \mathrm{~kg} / \mathrm{h}$ of air flow rate. The outlet boundaries are set to be outflows to simulate them being open to the atmosphere. The boundary conditions applied to the domains are presented in Figure 3.

The meshing process is an essential part in numerical work as it generates the finite control volumes in the flow domain where the flow equations are solved. The built-in meshing tool in the ANSYS Multi-Physics package was used. The dual injector was meshed using a structured non-conformal mesh due to the complex geometries presented. It is known that turbulent flow will be experienced in the injector and the pump system; consequently, some areas were identified for their 
high impact on accuracy of the simulation and its solution. The flow at the boundaries along the walls and through the axial and radial injectors are of high importance, and special meshing requirements are needed at such locations. Such requirements could be evaluated by analyzing the performance of the wall functions by using the $\mathrm{y}^{+}$parameter. Based on the turbulence model chosen and the geometry of injector, a $y^{+}$value of 15 was deemed sufficient and the thickness of the first layer was determined. The number of elements used to mesh the airlift injector was 236,862 and 274,529 nodes. While the number of elements used for the raceway were 322,512 and 342,940 nodes.

\section{Results}

The following sections will present the results obtained numerically and experimentally for each component of this study. Understanding how each the fluid flow inside the injector can give a good understanding of what to expect in a complete airlift system. While studying the flow characteristics of the raceway can provide a good indication of the performance capabilities of an airlift pump system operating in an aquaculture setting.

\section{1. Single-Phase Flow in the Dual Injection Airlift}

The dual injection airlift is a vital part of the operation of the raceway, and so understating the flow dynamics in the injector is essential to better understanding. Two sets of simulations were performed, using one operating fluid at a time for each set.

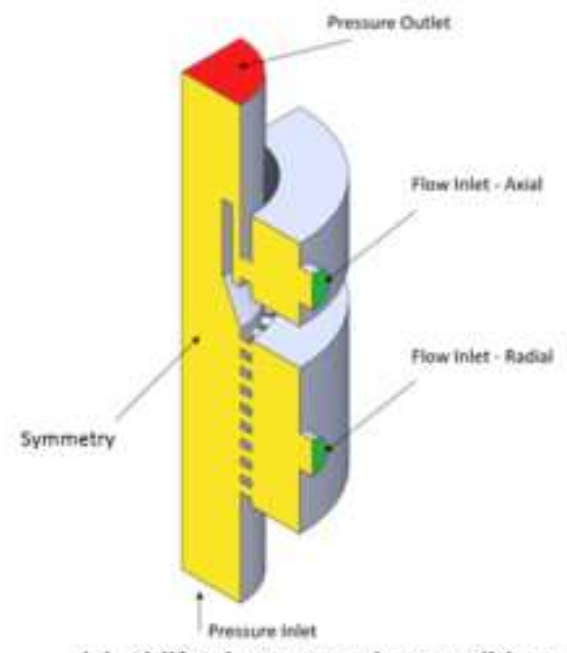

(a) Airlift Injector Boundary Conditions
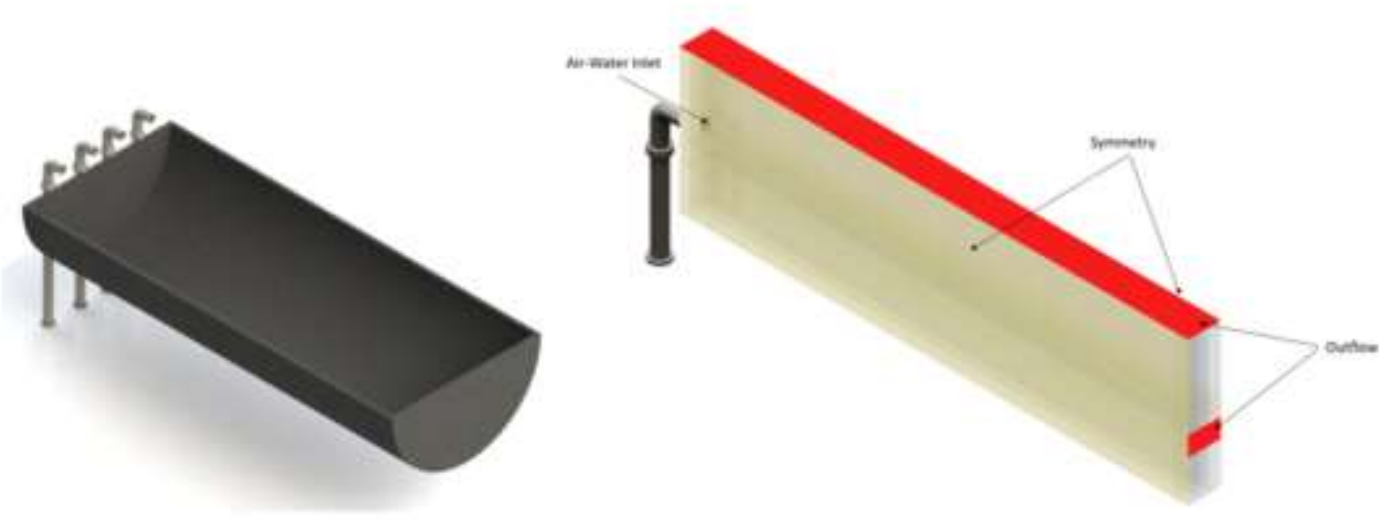

(b) Simplification of Raceway Geometry and Boundary Conditions

Fig. 3: Simplification of Raceway Geometry and Boundary Conditions.

The first set used only air and the second set was only water. The water properties were as follows: density: $998.2 \mathrm{~kg} / \mathrm{m}^{3}$ and viscosity: $1.003 \times 10^{-3} \mathrm{~kg} \cdot(\mathrm{m} / \mathrm{s})^{-1}$; while the air properties used were: density: $1.225 \mathrm{~kg} / \mathrm{m}^{3}$ and viscosity: $1.7894 \times 10^{-5}$ $\mathrm{kg} \cdot(\mathrm{m} / \mathrm{s})^{-1}$.The following sections discuss the results of each parameter analyzed for a sample where the inlet boundary condition chosen was $\mathrm{Q}=27.01 \mathrm{~m}^{3} / \mathrm{h}$ for both air and water separately.

The velocity field was obtained for the flow domain and the results are presented in Figure 4 where (a) is for the air flow only and (b) is water f] ${ }^{\cdots}$ only. The velocity distribution is similar throughout the system, which is expected since the same volumetric flow rate is used for both fluids. It is also apparent that the fluid velocity increases in the axial injector as it enters the restriction at the manifold. An increase in velocity is also noticed in the radial injector as the flow passes through the perforated section. The difference in velocity between the two fluids is attributed to the difference in density between air and water. An interesting observation was made by looking at the isometric view of the model, where the effect of each injector on the flow in the core of the airlift pump can be seen. The axial injector pushes the fluid along the wall of the pipe, while 
the radial injector pushes the fluid towards the center of the pipe. A radial velocity profile was also obtained at a line located on the symmetry boundary and is $0.145 \mathrm{~m}$ from the base of the airlift pump.

Static pressure is also an important flow parameter that describes the hydrodynamics of the flow inside the airlift injectors. Static pressure represents the force that is applied on a certain surface. It also dictates the flow of the fluid in any domain, as a fluid would always move from an area of high pressure to low pressure. Understanding the pressure distribution can also identify the areas causing high energy losses. The highest-pressure regions are found in the axial chamber. The flow enters from the inlet at a high velocity thus containing high kinetic energy, but as the flow reaches the constriction at the axial manifold, the wall boundary causes a high-pressure region by the manifold. Similarly, looking at the radial injector, the higher-pressure areas are found by the wall boundaries between each radial opening. There is a big difference in the pressure magnitude between the two fluid cases. The mass difference between air and water is the biggest contributor for the pressure magnitude difference. The distribution of pressure in the dual injectors is similar for both cases, which meets the expectations based on the boundary conditions applied. The static pressure solution from the air flow case was used as the validation parameter of this numerical work. A lab experiment was performed, where the pressure across each of the injector inlets was measured using the flow control meter and compared to the pressure obtained numerically.

The pressure across the injector was calculated by finding the area average of static pressure at the injector inlets and subtracting the area averaged static pressure at the pump pressure outlet. Figure 5 shows the results of the numerical simulation for both the $\mathrm{k}-\varepsilon$ and $\mathrm{k}-\omega$ along with the experimental validation.
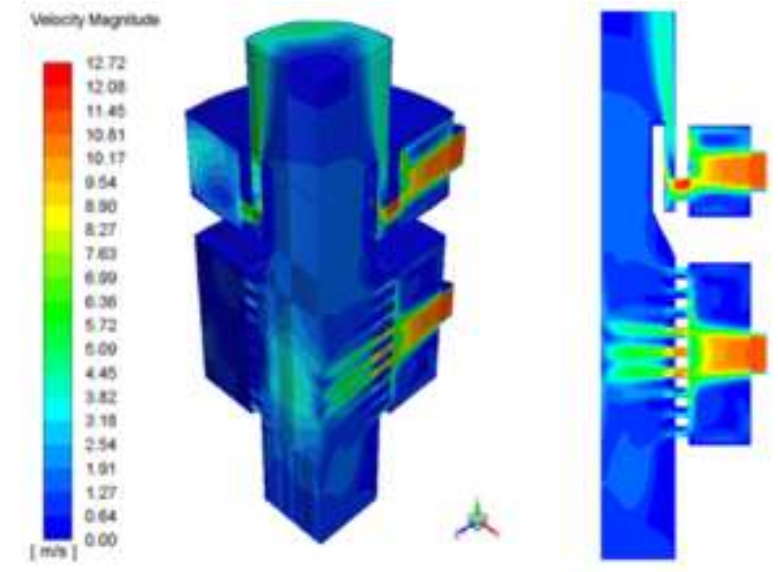

(a) Air Flow Only
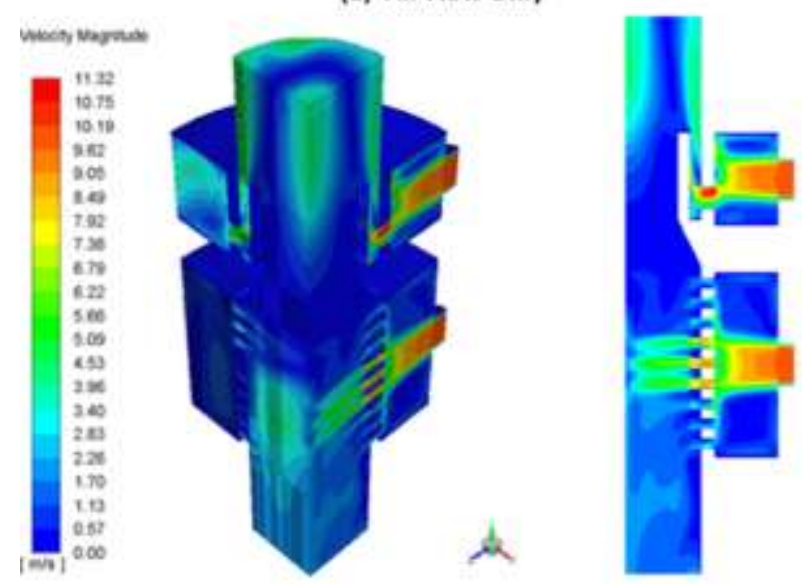

(b) Water Flow Only

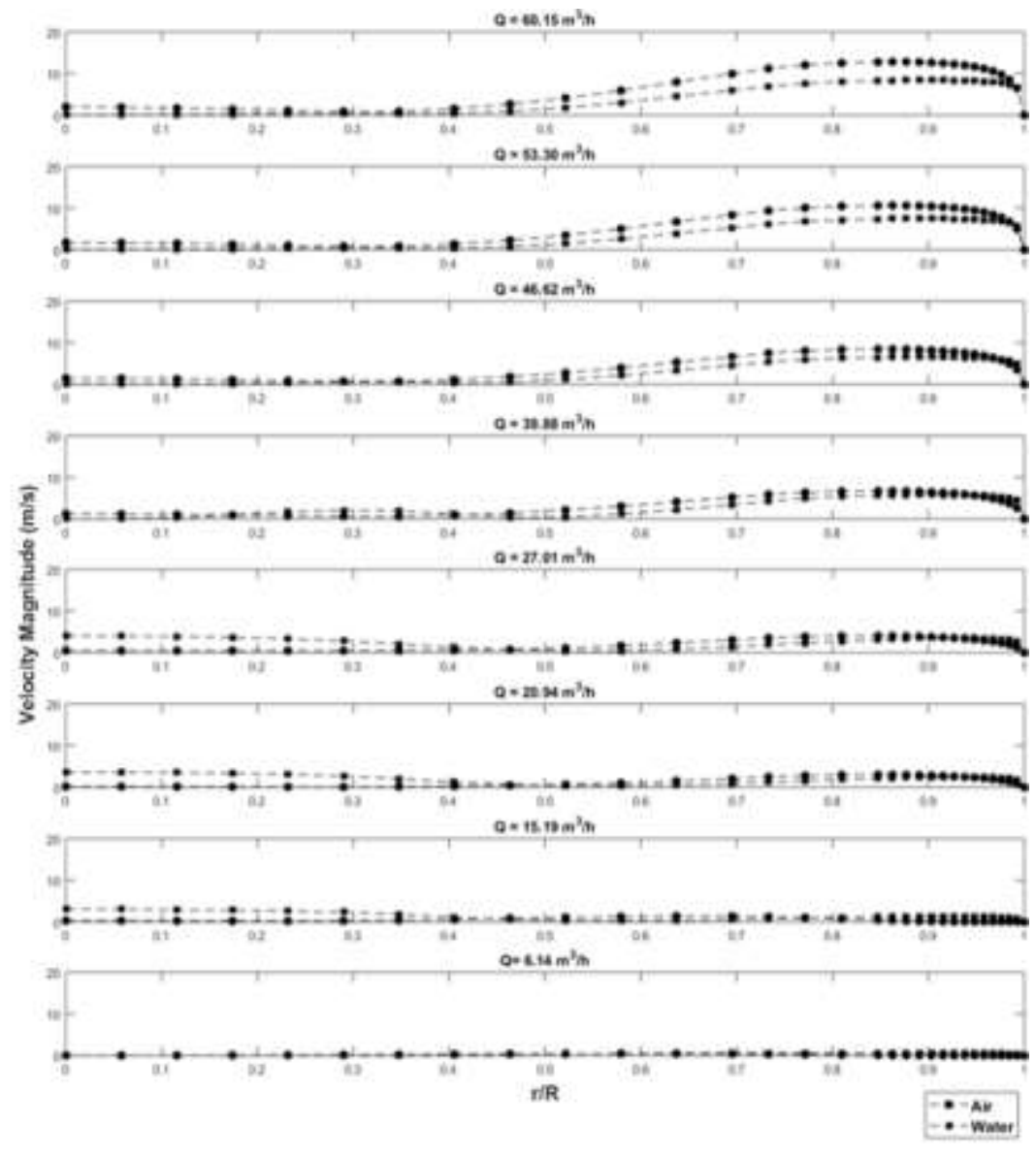

(c) Radial Velocity Profile for Single-Phase Flow Downstream of Pump Injector

Fig. 4: Velocity Contours of Single-Phase Flow Through Airlift Injector. 


\section{2. Flow in Aquaculture Raceway}

The raceway simulation combines the study of the operation of the airlift pump and its effect on an aquaculture system. The ability to test various airlift system designs and determine their performance impact on any system would be a huge advantage in the commercialization process of aquaculture facilities. The transient parameters used for this work included a time step size of $1 \times 10^{-2}$ with 40 iterations running per time step. Water velocity measurements were taken at different locations to provide a velocity profile to which the simulations were compared. The stream wise velocity was measured in the raceway experimentally using the acoustic Doppler velocimeter. Velocity monitors were placed at a total of 48 points at various lengths and depths in the raceway.

For CFD, velocity monitors were placed along the center line of the raceway as well on the symmetry boundaries. The rest of the points were placed on the symmetry boundaries to capture the velocity magnitude at the intersection between the other sections of the raceway. The velocity comparison between the numerical solution and the experimental measurements in Figure 6 show that most of the data points fall within the experimental error bars provided from the ADV. velocity values obtained by the velocimeter. The experimental velocity magnitudes at one of the side boundaries also seemed to have different values when compared to the numerical symmetry solution, or even the opposite side boundary. Some deviation between the two results also exists. This caused a concentration in the flow to occur more to one side of the raceway than the other. Those velocity readings still show the overall velocity magnitudes required for the operation of the raceway despite the slight bias caused by the construction of the system. The numerical solutions obtained through the simulation show that the same velocity magnitudes were achieved through computational fluid dynamics. Utilizing this method, it would be possible to use CFD to predict the operational flows in future designs of aquaculture systems while still being in the design phase of a project. This could lead to further innovative designs and their implementation into aquaculture systems, helping to make such systems more economical and widespread.
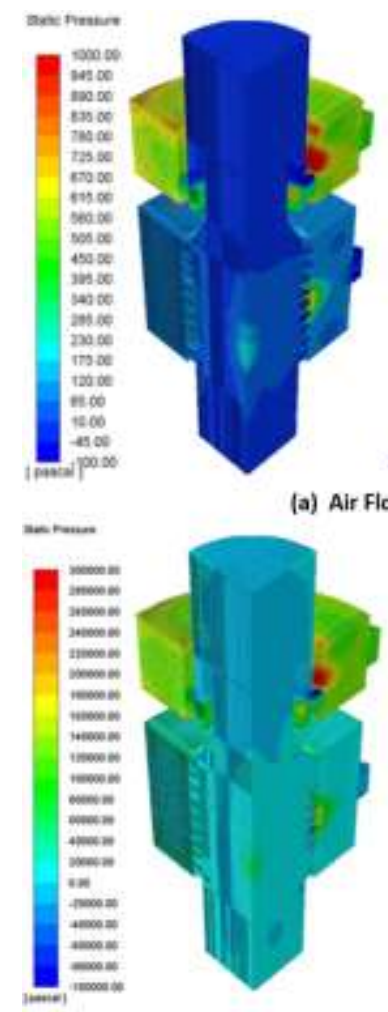

(a) Air Flow Only
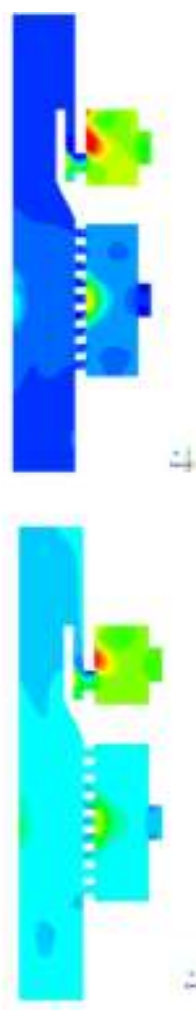

b) Water Flow Only

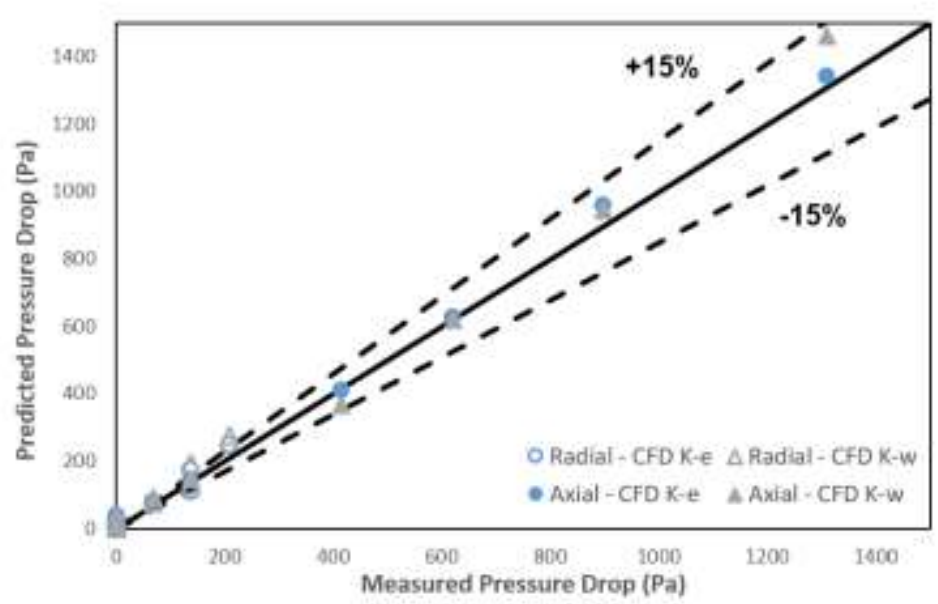

(c) Experimental Validation of Pressure Drop Across Airlift Pump Injectors

Fig. 5: Static Pressure Contours of Single-Phase Flow Through Airlift Injector Along with Air Experimental Validation of Pressure Drop for Air Flow Only. 


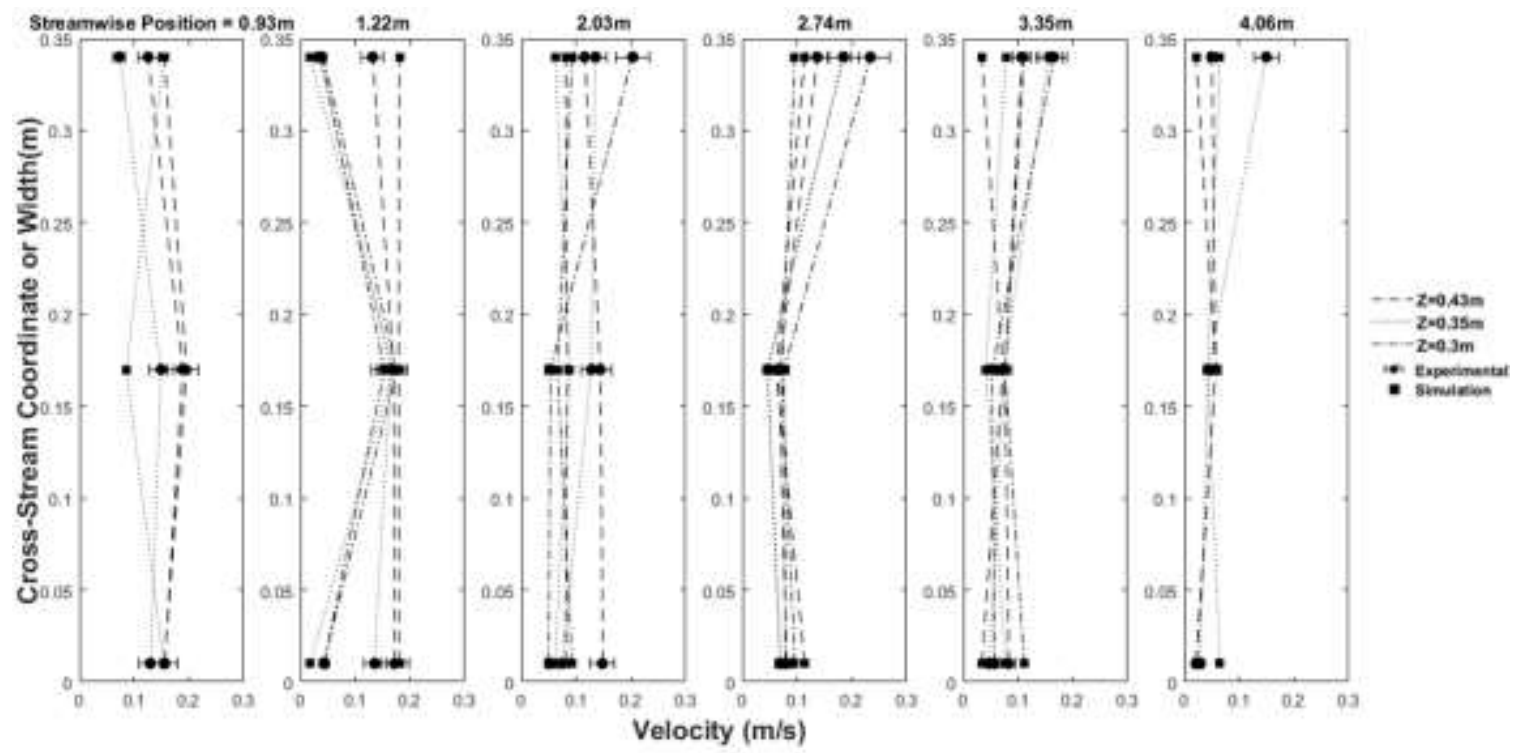

Fig. 6: Stream wise Velocity Profile in Raceway.

\section{Conclusion}

An experimental and numerical study was performed on a dual injection airlift pump as well as on an airlift pump system integrated aquaculture raceway. The dual injection airlift model was analyzed to study the hydrodynamics of the flow and the effects of each injector. It was found that the axial injector provided higher flow velocities at the wall, while the effects of the radial injectors were more profound near the center of the airlift pump. The pressure drop obtained across the airlift pump using a numerical simulation was validated against experimental pressure readings at the injectors. It was found that the pressure drop across the axial injector was significantly higher relative to the radial injector. This is mainly due to the difference in chamber size, where the axial chamber is smaller to the radial one. Based on the experimental validation it was also determined that the K- $\varepsilon$ turbulence model would be more appropriate for further simulations. The aquaculture raceway study aimed to study the operational condition when operating with an integrated airlift pump system. An experimental setup was built which included four $1.016 \times 10^{-1} \mathrm{~m}$ airlift pumps and installed at an aquaculture facility. Velocity measurements were obtained along and across the raceway to create velocity profiles. A section of the raceway was modelled, and a free surface simulation was performed to capture the interaction between the air-water inlet of the airlift with the raceway boundary. The results showed that when using CFD, the predicted velocity magnitude matched that which was observed in the field. These results showed that the use of computational fluid dynamics could be integrated into the design process of airlift pump injectors. This would permit the integration of these pumps into aquaculture systems by obtaining an accurate prediction of the operating conditions.

\section{Acknowledgements}

The authors wish to acknowledge the support received from the Ontario Ministry of Agriculture and Rural Affairs (OMAFRA) under the Gryphon's LAAIR (Leading to Accelerated Adoption of Innovative Research) Grant No. 29633. FloNergia Inc. is also acknowledged for providing the airlift pumps for testing.

\section{References}

[1] W. H. Ahmed and H. M. Badr, "Dual-injection airlift pumps: An enhanced performance," Part. Sci. Technol., vol. 30, no. 6, pp. 497-516, 2012.

[2] The World Bank, "Sustainable Aquaculture," 2014. [Online]. Available:

http://www.worldbank.org/en/topic/environment/brief/sustainable-aquaculture 
[3] F. W. Wheaton, Aquacultural Engineering. Krieger, 1993.

[4] S. Spotte, Fish and Invertebrate Culture: Water Management in Closed Systems. Wiley, 1979.

[5] N. C. Parker and M. A. Suttle, "Design of airlift pumps for water circulation and aeration in aquaculture," Aquac. Eng., vol. 6, no. 2, pp. 97-110, 1987.

[6] W. A. Wurts, S. G. Mcneill, and D. G. Overhults, "Performance and design characteristics of airlift pumps for field applications," World Aquac., vol. 25, no. December, pp. 51-55, 1994.

[7] O. Lekang, Aquaculture Engineering. 2013.

[8] J. Ebeling, "Overview of Systems Engineering," pp. 73, 2006.

[9] YSI Inc. and SonTek, "FlowTracker ${ }^{\circledR}$ Handheld ADV ${ }^{\circledR}$ Technical Manual," 2007.

[10] ANSYS, ANSYS FLUENT Theory Guide. 2011. 